\title{
Breast Cancer: Knowledge, Attitudes on Risk Factors and Means of Screening by Medical Students from Lomé, Togo
}

\author{
Tchin Darre ${ }^{1}$, Mazamaesso Tchaou ${ }^{2}$, Toukilnan Djiwa1 ${ }^{1}$ Essossinam L. Tcharié1, \\ Luc Valère C. Brun ${ }^{3}$, Fifonsi A. Gbeasor-Komlanvi', Bidamin N'Timon ${ }^{2}$, Abdoulatif Amadou², \\ Panakinao Simgban' ${ }^{1}$, Didier Koumavi Ekouévi ${ }^{4}$, Gado Napo-Koura ${ }^{1}$
}

\author{
${ }^{1}$ Department of Pathology, University Teaching Hospital of Lomé, Lomé, Togo \\ ${ }^{2}$ Department of Radiology, University Teaching Hospital of Lomé, Lomé, Togo \\ ${ }^{3}$ Department of Pathology, University Teaching Hospital of Parakou, Parakou, Bénin \\ ${ }^{4}$ Department of Health and Epidemiology, University of Lomé, Lomé, Togo \\ Email: ^paolodarre@yahoo.fr, joseph_tchaou@yahoo.fr, constantdjiwa@gmail.com, essossitcharie20@gmail.com, \\ luc.brun2013@gmail.com, fifonsi.gbeasor@gmail.com,cntimon@yahoo.fr, amadoulatif@yahoo.fr, \\ panakinaopsr@gmail.com, didier.ekouevi@gmail.com, fgnapo@yahoo.fr
}

How to cite this paper: Darre, T., Tchaou, M., Djiwa, T., Tcharié, E.L., Brun, L.V.C., Gbeasor-Komlanvi, F.A., N'Timon, B., Amadou, A., Simgban, P., Ekouévi, D.K. and Napo-Koura, G. (2020) Breast Cancer: Knowledge, Attitudes on Risk Factors and Means of Screening by Medical Students from Lomé, Togo. Advances in Breast Cancer Research, 9, 127-137.

https://doi.org/10.4236/abcr.2020.94011

Received: September 1, 2020

Accepted: October 10, 2020

Published: October 13, 2020

Copyright $\odot 2020$ by author(s) and Scientific Research Publishing Inc. This work is licensed under the Creative Commons Attribution International License (CC BY 4.0).

http://creativecommons.org/licenses/by/4.0/

\begin{abstract}
Background: Breast cancer is the leading cause of cancer-related death in women around the world. The objective of this study was to assess knowledge and attitudes about breast cancer screening among students in the Faculty of Health Sciences at the University of Lomé. Methods: This was a prospective descriptive transversal study conducted among students enrolled in the Faculty of Health Sciences (FSS) of the University of Lomé (UL) in the 2019 school year account 2020. The purpose of this study was to assess the knowledge and attitudes of medical students about breast cancer screening. Results: In total, the questionnaire was completed by 934 students, for a response rate of $57.1 \%$. The most frequently mentioned risk factors were the presence of a family history of breast cancer $(\mathrm{n}=799,85.55 \%)$ and the use of oral or injectable contraceptives $(n=606,64.88 \%)$. There is a statistically significant link between the participants' knowledge of the self-examination and clinical examination of the breasts and certain socio-demographic characteristics, namely age (OR $=0.2,95 \% \mathrm{CI}[0.11-0.75]$, p-value $<0.0001)$, the level of study $(\mathrm{OR}=1.5,95 \% \mathrm{CI}[0.55-2.46]$, p-value $=0.0054)$, the follow-up of a course on breast cancer $(\mathrm{OR}=2.63,95 \% \mathrm{CI}[0.32-4.33]$, $\mathrm{p}$-value $=0.009)$ and the effectiveness of an internship in a gynecology-obstetrics department $(\mathrm{OR}=$ $0.77,95 \%$ CI [0.49 - 2.56], p-value < 0.0001). Similarly, there is a statistically significant link between participants' knowledge of mammography and cer-
\end{abstract}


tain socio-demographic characteristics, namely age ( $\mathrm{OR}=0.75,95 \% \mathrm{CI}[0.50$ - 0.84], p-value $=0.0005)$, the level of study $(\mathrm{OR}=1.92,95 \%$ CI $[1.11-3.46]$, $\mathrm{p}$-value $<0.0001$ ), the follow-up of a course or training on breast cancer (OR $=2.44,95 \% \mathrm{CI}[0.08-3.91]$, p-value $<0.0001)$ and the effectiveness of an internship in a gynecology-obstetrics department $(\mathrm{OR}=0.62,95 \%$ CI $[0.33$ 0.85 ], p-value < 0.0001). Conclusion: Knowledge and attitudes related to breast cancer screening have been found to be generally satisfactory to medical students. Active measures are needed to develop educational programs for health personnel, which could enable them to disseminate knowledge and positively influence patient attitudes.

\section{Keywords}

Breast Cancer, Screening, Knowledge, Medical Students, Togo

\section{Background}

Breast cancer is the most common cancer in women worldwide and represents a public health concern [1]. In 2018, more than 2 million new cases of breast cancer were diagnosed worldwide, representing $11.6 \%$ of all cancers [1]. Breast cancer is also the most common cause of cancer-related death in women [1] [2]. The incidence of breast cancer is increasing at a high rate and is expected to reach more than 19.3 million women by 2025 , the majority being from sub-Saharan Africa [2]. Although there has been immense progress in the treatment of breast cancer, the prognosis remains poor in developing countries [3] [4]. A major cause of the poor prognosis could be a delay in diagnosis. When breast cancer is diagnosed at an early stage, the prognosis is good, with reduced morbidity and mortality [5] [6]. Therefore, measures must be taken to ensure early detection and prompt treatment. Two essential strategies for early detection include early diagnosis and screening [6]. An important aspect of early diagnosis includes increasing awareness of early signs of cancer among doctors, nurses, other health professionals, and the general population [7]. Screening, on the other hand, includes the use of simple tests to identify people with cancer even before symptoms appear [8]. Self-examination, clinical examination of the breast, and mammography are well-known screening methods for breast cancer [6] [7].

In Togo, awareness is very low and patients regularly present with advanced stages of breast cancer [9] [10]. Lack of basic knowledge and an effective system for disseminating information on breast cancer threatens the lives and well-being of women [10]. Breast cancer silently kills women mainly those who have no knowledge and who are still unaware of breast cancer and diagnostic breast screening methods for early detection. Doctors, medical students, nurses and other health professionals must play a key role in disseminating information to the general population about breast cancer screening. The objective of this study 
was to assess knowledge and attitudes about breast cancer screening among students in the Faculty of Health Sciences at the University of Lomé.

\section{Methods}

\subsection{Study Plan and Sampling}

A cross-sectional study was carried out among students regularly enrolled in the Faculty of Health Sciences (FSS) of the University of Lomé (UL) in the 2019-2020 school year account. Togo is a country of $56,600 \mathrm{Km}^{2}$, with an estimated population of 7,200,000 located between Ghana in the west and Benin in the east. The total number of regularly enrolled students at UL's FSS was 1635. The minimum sample size (n) was calculated using the following formula:

$$
n=(1.96)^{2} \times p \times q / d^{2}
$$

1.96: value corresponding to the $95 \%$ confidence level.

$p$ : estimated prevalence rate of Cap $=0.5$.

$q=1-p=(1-0.5)=0.5$.

$d$ : desired degree of precision $=0.05$.

$n=(1.96)^{2} \times(0.5 \times 0.5) /(0.05)^{2}=384.16$.

The minimum sample size $\mathrm{n}=384.16$ or 385 students. We enrolled 934 students out of 1635 corresponding to $57.1 \%$ of the total student body at the FSS. It took place from January 1 to March 31, 2020, for a period of 3 months.

\subsection{Data Collection}

The data were collected using a self-administered anonymous structured questionnaire, divided into three (03) main parts. The survey questionnaire included an introductory first part detailing the objectives and methodology of the study. The second part sought information on the socio-demographic characteristics of the students (age, sex, level of medical study, previous courses on breast cancer, and internship in an obstetrics gynecology department) and risk factors for breast cancer. The third part dealt with their level of knowledge on breast cancer screening, based on self-examination and clinical examination of the breasts, and mammography. To all of these questions in Part Three, subjects should answer "Yes" or "No".

The questionnaire was pre-tested on 50 students, without any particular problem.

\subsection{Data Management and Analysis}

Data was entered twice in Microsoft Excel to reduce data entry errors and then exported to Epi Info version 7 software. A descriptive analysis was carried out with a view to highlighting the characteristics of the different qualitative and quantitative variables. We used percentages for qualitative variables and means with their standard deviations for quantitative variables. The statistical tests used were the Paerson Chi-square test for the qualitative variables and the Student 
test for the quantitative variables. The significance threshold was set at 0.05 .

\section{Results}

\subsection{Epidemiological Data}

Table 1 summarizes the socio-demographic characteristics of the students. The questionnaire was completed by 934 students, with an overall response rate of $57.1 \%$. The mean age of the subjects was $22.7 \pm 3.8$ years, with the range of 16 and 34 years. Eight hundred and twenty-one (821) or $80.73 \%$ of the students were 25 years of age or less. These were $661(70.8 \%)$ male subjects and 273 (29.2\%) female subjects, representing a sex ratio (M/F) of 2.4. According to the university course, 450 (48.1\%) were in the Doctorate cycle, $122(13.1 \%)$ in the Master cycle and 362 (38.8\%) in the License cycle. Three hundred and nine (309) or $33.1 \%$ of the students had received no training or course in breast cancer. One hundred and fifteen (115) or 12.3\%, 64 (6.9\%) and 446 (47.8\%) had courses on breast cancer, with a delay respectively of less than 6 months, between 6 months and 1 year, and more than a year. The internship in the gynecology-obstetrics department was never carried out by 338 (36.2\%).

Table 1. Epidemiological characteristics.

\begin{tabular}{|c|c|c|c|}
\hline & $\mathbf{N}$ & Value & $\%$ \\
\hline Sex & 934 & & \\
\hline Male & & 661 & 70.8 \\
\hline Female & & 273 & 29.2 \\
\hline Age (years) & 934 & & \\
\hline$[16-20]$ & & 310 & 33.2 \\
\hline$[20-25]$ & & 359 & 38.4 \\
\hline$[25-30]$ & & 257 & 27.5 \\
\hline$[30-34]$ & & 8 & 0.9 \\
\hline Study cycle & 934 & & \\
\hline Bachelor & & 362 & 38.8 \\
\hline Master & & 122 & 13.1 \\
\hline Doctorate & & 450 & 48.1 \\
\hline Training/courses on breast cancer & 934 & & \\
\hline$\leq 6$ months & & 115 & 12.3 \\
\hline Between 6 months and 1 year & & 64 & 6.9 \\
\hline$>1$ year & & 446 & 47.8 \\
\hline Any & & 309 & 33.0 \\
\hline Internship in a gynecology-obstetric department & 934 & & \\
\hline Yes & & 596 & 63.8 \\
\hline No & & 338 & 36.2 \\
\hline
\end{tabular}




\subsection{Knowledge of Risk Factors}

The most mentioned risk factor was the presence of a family history of breast cancer $(n=799,85.55 \%)$, second comes the use of oral or injectable contraceptives reported by $(n=606,64.88 \%)$. The other factors most often reported by students were advanced age $(n=512,54.8 \%)$, tobacco $(356,38.1 \%)$, nulliparity $(\mathrm{n}=298,31.9 \%)$. The risk factors least cited by the students were, early menstrual age $(\leq 12$ years) $(n=207,22.2 \%)$, diet $(n=201,21.5 \%)$, late menopause ( $n$ $=162,17.3 \%$ ).

\subsection{Knowledge about Breast Cancer Screening}

Regarding self-examination and clinical examination of the breasts, as a means of screening for breast cancer, 781 (83.6\%) students across all cycles gave a positive response. $609(65.2 \%)$ have ever practiced or helped to do the clinical breast exam. Students able to recognize an inflammatory breast or breast nodule were $100 \%$ and $63 \%(\mathrm{n}=588)$ of the participants, respectively. For students in the Doctorate and Master cycles, 449 (99.8\%) and 120 (98.4\%) respectively had a good knowledge of clinical examination and breast self-examination. There is a statistically significant link between the participants' knowledge of the self-examination and clinical examination of the breasts and certain socio-demographic characteristics, namely age $(\mathrm{OR}=0.2,95 \% \mathrm{CI}[0.11-0.75]$, $\mathrm{p}$-value $<0.0001)$, the level of study $(\mathrm{OR}=1.5,95 \% \mathrm{CI}[0.55-2.46]$, $\mathrm{p}$-value $=$ $0.0054)$, the follow-up of a course on breast cancer ( $\mathrm{OR}=2.63,95 \% \mathrm{CI}[0.32$ 4.33 , p-value $=0.009)$ and the effectiveness of an internship in a gynecology-obstetrics department ( $\mathrm{OR}=0.77,95 \% \mathrm{CI}$ [0.49 - 2.56], p-value < 0.0001). On the other hand, there is no statistically significant link between the participants' knowledge of the clinical breast self-examination and examination, and the gender of the participants $(\mathrm{OR}=1.44,95 \% \mathrm{CI}[1.01-1.76], \mathrm{p}$-value $=0.988)$ (Table 2).

They were 703 (75.3\%) to know mammography as a means of breast cancer screening, divided into 482 boys and 221 girls. Two hundred and thirty-seven (237) undergraduate students had no knowledge of breast cancer screening with mammography. For students in the Master and Doctorate cycles, respectively $110(84.21 \%)$ and 448 (98.87\%) had knowledge of mammography as a means of screening. There is a statistically significant link between participants' knowledge of mammography and certain socio-demographic characteristics, namely age $(\mathrm{OR}=0.75,95 \% \mathrm{CI}[0.50-0.84]$, $\mathrm{p}$-value $=0.0005)$, the level of study $(\mathrm{OR}=$ $1.92,95 \% \mathrm{CI}[1.11-3.46]$, p-value $<0.0001)$, the follow-up of a course or training on breast cancer $(\mathrm{OR}=2.44,95 \% \mathrm{CI}[0.08-3.91]$, p-value $<0.0001)$ and the effectiveness of an internship in a gynecology-obstetrics department $(\mathrm{OR}=0.62$, $95 \%$ CI $[0.33$ - 0.85], p-value < 0.0001$)$. On the other hand, there is no statistically significant link between the participants' knowledge of the mammography and the gender of the participants $(\mathrm{OR}=0.76,95 \% \mathrm{CI}[0.34-3.88]$, $\mathrm{p}$-value $=$ 0.623) (Table 3). 
Table 2. Socio-demographic characteristics VS knowledge of self-examination and clinical breast examination.

\begin{tabular}{|c|c|c|c|c|c|}
\hline \multirow[t]{2}{*}{ socio-demographic characteristics } & \multicolumn{5}{|c|}{$\begin{array}{l}\text { Univariate analysis (knowledge of self-examination and } \\
\text { clinical breast examination) }\end{array}$} \\
\hline & $\mathrm{n} / \mathrm{N}$ & $\%$ & OR & $95 \% \mathrm{CI}$ & p-value \\
\hline Sex & & & & & 0.988 \\
\hline Male & $550 / 661$ & 83.2 & 1 & - & \\
\hline Female & $231 / 273$ & 84.6 & 1.44 & {$[1.01-1.76]$} & \\
\hline Age (years) & & & & & $<0.0001$ \\
\hline$\leq 23$ & $357 / 507$ & 70.4 & 1 & - & \\
\hline$>23$ & $424 / 427$ & 99.3 & 0.2 & {$[0.11-0.75]$} & \\
\hline Study cycle & & & & & 0.0054 \\
\hline Bachelor & $212 / 362$ & 58.6 & 1 & - & \\
\hline Master & $120 / 122$ & 98.4 & 1.5 & {$[1.19-2.46]$} & \\
\hline Doctorate & $449 / 450$ & 99.8 & 0.9 & {$[0.55-1.28]$} & \\
\hline \multicolumn{5}{|c|}{ Follow up on your latest breast cancer training/courses } & 0.009 \\
\hline$<6$ months & $112 / 115$ & 97.4 & 1 & - & \\
\hline Between 6 months and 1 year & $64 / 64$ & 100 & 0.88 & {$[0.32-1.98]$} & \\
\hline$>1$ year & $445 / 446$ & 99.8 & 2.18 & {$[2.05-3.57]$} & \\
\hline Any & $160 / 309$ & 51.8 & 2.63 & {$[1.08-4.33]$} & \\
\hline \multicolumn{5}{|c|}{ Internship in a gynecology-obstetric department } & $<0.0001$ \\
\hline Yes & $591 / 596$ & 99.2 & 1 & - & \\
\hline No & $190 / 338$ & 56.2 & 0.77 & {$[0.49-2.56]$} & \\
\hline
\end{tabular}

Table 3. Socio-demographic characteristics VS knowledge of Mammography.

\begin{tabular}{|c|c|c|c|c|c|}
\hline \multirow[t]{2}{*}{ Socio-demographic characteristics } & \multicolumn{5}{|c|}{$\begin{array}{c}\text { Univariate analysis } \\
\text { (knowledge of Mammography) }\end{array}$} \\
\hline & $\mathrm{n} / \mathrm{N}$ & $\%$ & OR & $95 \% \mathrm{CI}$ & p-value \\
\hline Sex & & & & & 0.623 \\
\hline Male & $482 / 661$ & 72.9 & 1 & - & \\
\hline Female & $201 / 273$ & 73.6 & 0.76 & {$[0.34-3.88]$} & \\
\hline Age (years) & & & & & 0.0005 \\
\hline$\leq 23$ & $261 / 507$ & 51.5 & 1 & - & \\
\hline$>23$ & $422 / 427$ & 98.8 & 0.75 & {$[0.50-0.84]$} & \\
\hline Study cycle & & & & & $<0.0001$ \\
\hline Bachelor & $125 / 362$ & 34.5 & 1 & - & \\
\hline Master & $110 / 122$ & 90.2 & 1.92 & {$[1.74-3.46]$} & \\
\hline Doctorate & $448 / 450$ & 99.6 & 1.21 & {$[1.11-1.73]$} & \\
\hline
\end{tabular}

Follow up on your latest breast cancer training/courses

$<0.0001$ 


\begin{tabular}{lccccc} 
Continued & & & & & \\
\hline$<6$ months & $98 / 115$ & 85.2 & 1 & - & \\
Between 6 months and 1 year & $62 / 64$ & 96.9 & 0.36 & {$[0.08-0.92]$} & \\
$\quad>1$ year & $434 / 446$ & 97.3 & 1.89 & {$[1.55-2.09]$} & \\
Any & $89 / 309$ & 28.8 & 2.44 & {$[2.16-3.91]$} & \\
Internship in a gynecology-obstetric department & & & & & $<0.0001$ \\
$\quad$ Yes & $573 / 596$ & 96.1 & 1 & - & \\
No & $110 / 338$ & 32.5 & 0.62 & {$[0.33-0.85]$} & \\
\hline
\end{tabular}

\section{Discussion}

Breast cancer is the most common type of cancer among women in Togo [9]. It occurs more and more in young Togolese women and the diagnosis is often made at advanced stages [10]. Breast cancer awareness and the practice of screening methods facilitate early detection of breast cancer, thereby improving the chances of survival and better health outcomes [11]. This study, knowledge, attitudes on risk factors and means of breast cancer screening by medical students, was the first to be conducted in Togo. Our study provides useful information to help fill the data gap on knowledge of breast cancer screening in Togo. Studies in developed countries show that the attitude and orientation of health care providers are important determinants of the use of breast cancer screening programs [11] [12].

Established risk factors for breast cancer include reproductive and hormonal factors (first menstruation, late menopause; nulliparity; exogenous estrogen), genetics, age, adiposity, alcohol consumption and low socioeconomic status [13]. The students' response to the risk factors for breast cancer was generally satisfactory, but still deserves further strengthening in order to better understand its risk factors. Their perfect control of risk factors will depend on the quality of the information disseminated within the general population. A lower level of knowledge and awareness of risk factors for breast cancer appears to cause difficulties in recognizing the symptoms of breast cancer, greater severity of the disease and more advanced stages of the disease due to longer time before asking for help [13] [14]. On the other hand, a low level of knowledge of risk factors often results in bad attitudes and bad behaviors about maintaining a healthy lifestyle and about breast cancer screening methods [15]. Therefore, it is important to strengthen students' knowledge so that they can better educate the public about the risk factors associated with breast cancer so that individuals can integrate lasting attitudes and lifestyle changes.

Students in $83.6 \%$ gave breast self-exam and clinical breast screening. Although self-examination is the most commonly used early detection technique, evidence of its effectiveness is discussed [16] [17]. This technique can lead to over detection of nodules leading to unnecessary visits to the doctor and expenses related to the diagnosis, which is not desirable in the context of develop- 
ing countries where health facilities and resources are limited [16]. However, although current evidence does not support self-examination as a breast cancer screening approach, teaching breast self-examination at the individual level in countries where most women with breast cancer advanced disease may improve awareness of breast cancer and lead to an earlier stage of diagnosis [18]. Clinical breast examination has the advantage of being a relatively simple and inexpensive technique for the early detection of breast tumors [10]. It should be done adequately by trained health workers [18]. The role of self-examination and clinical breast examination is important in areas where mammography may not be available for financial and accessibility reasons [19]. In addition, statistics indicate that $90 \%$ of breast nodules are discovered by women themselves [19].

As for the students' knowledge of mammography as a means of screening for breast cancer, $75.3 \%$ were aware of it. Mammography has long been regarded as the gold standard for breast cancer screening in high-income countries, and has led to significant reductions in mortality rates among women aged 50 and over who have participated in organized breast cancer programs mammography screening [20]. Mammographic screening proves to be beneficial when it is carried out in an organized and regular manner in the form of a national public health policy or when the per capita income of the population allows it to absorb most of the costs [21]. Mammography screening is financially and technically difficult to implement and maintain, requiring high-quality machines, well-trained radiologists and technicians, and investment in pathology and treatment facilities [21] [22]. Therefore, organized screening is difficult in developing countries. Socioeconomic dependence and late diagnosis reflect higher rates of breast cancer morbidity and mortality in developing countries [23]. The impact of mammography screening may be more beneficial in developing countries than what has been observed in developed countries [24]. This structure can be assessed using indicators relating to the quality or methodology of the diagnosis. This will allow us to better understand the real impact of mammography screening in developing countries [25] [26].

\section{Conclusion}

The knowledge and attitudes on the means of breast cancer screening by medical students in Lomé have proved to be generally satisfactory. However, the study population was fairly well aware of the availability and usefulness of screening methods. Although mammography screening has reduced mortality in many high-income countries, it is currently not available in most countries in sub-Saharan Africa and may not be the most appropriate method of early detection for this region. In Togo, there is not yet a real structured health policy for breast cancer screening by mammography. Self-examination and clinical breast examination may be a more appropriate and effective approach to reduce mortality from breast cancer in Togo, where resources to implement and maintain population-based screening programs are limited. It also turns out to be essential 
to properly train medical students who are future doctors to get better involved in the prevention and screening of breast cancer in Togo.

\section{Ethics Approval and Consent to Participate}

This study was approved by the "Comité de Bioéthique pour la Recherche en Santé (CBRS)" (Bioethics Committee for Health Research) from the Togo Ministry of Health, Ref No: 0101/2016/MS/CAB/DGS/DPLET/CBRS). Authorization was obtained from the Dean of the FSS of University of Lomé, to whom we sent a letter of authorization request explaining the objectives and methodology of the study. Students were assured that participation in the survey was voluntary and anonymous. They were also assured of the confidentiality of the information provided and that all data should be treated anonymously. Written informed consent was obtained prior to participation.

\section{Availability of Data and Materials}

Extracted data are with the authors and available for sharing on request.

\section{Authors' Contribution}

TD and MT are responsible for the design of the study, undertook the field study, performed data collection, analysis, and interpretation, and wrote the manuscript. TDj, ELT, LVCB, FAGK, BN, AA, PS and DKE participated in the design of the study, supervised the data collection, and participated in the data analysis. GNK is responsible for the overall scientific management of the study, the analysis and interpretation, and preparation of the final manuscript.

\section{Conflicts of Interest}

The authors declare no conflicts of interest regarding the publication of this paper.

\section{References}

[1] Bray, F., Bray, F., Ferlay, J., Soerjomataram, I., Siegel, R.L., Torre, L.A. and Jemal, A. (2018) Global Cancer Statistics 2018: GLOBOCAN Estimates of Incidence and Mortality Worldwide for 36 Cancers in 185 Countries. CA: A Cancer Journal for Clinicians, 68, 394-424. https://doi.org/10.3322/caac.21492

[2] Adeloye, D., et al. (2018). Estimating the Incidence of Breast Cancer in Africa: A Systematic Review and Meta-Analysis. Journal of Global Health, 8, Article ID: 010419.

[3] Brinton, L.A., Figueroa, J.D., Awuah, B., Yarney, J., Wiafe, S., Wood, S.N., Ansong, D., Nyarko, K., Wiafe-Addai, B. and Clegg-Lamptey, J.N. (2014) Breast Cancer in Sub-Saharan Africa: Opportunities for Prevention. Breast Cancer Research and Treatment, 144, 467-478. https://doi.org/10.1007/s10549-014-2868-z

[4] Joko-Fru, W.Y., et al. (2020) Breast Cancer Survival in Sub-Saharan Africa by Age, Stage at Diagnosis and Human Development Index: A Population-Based Registry Study. International Journal of Cancer, 146, 1208-1218.

https://doi.org/10.1002/ijc.32406 
[5] Black, E. and Richmond, R. (2019) Improving Early Detection of Breast Cancer in Sub-Saharan Africa: Why Mammography May Not Be the Way Forward. Globalization and Health, 15, Article No. 3. https://doi.org/10.1186/s12992-018-0446-6

[6] Toan, D.T.T., Son, D.T., Hung, L.H., Minh, L.N., Mai, D.L. and Hoat, L.N. (2019) Knowledge, Attitude, and Practice Regarding Breast Cancer Early Detection among Women in a Mountainous Area in Northern Vietnam. Cancer Control, 26, 1-5. https://doi.org/10.1177/1073274819863777

[7] Dibisa, T.M., Gelano, T.F., Negesa, L., Gebrehawareya, T. and Abate, D. (2019) Breast Cancer Screening Practice and Its Associated Factors among Women in Kersa District, Eastern Ethiopia. The Pan African Medical Journal, 33, 144. https://doi.org/10.11604/pamj.2019.33.144.18062

[8] Pace, L.E. and Shulman, L.N. (2016) Breast Cancer in Sub-Saharan Africa: Challenges and Opportunities to Reduce Mortality. The Oncologist, 21, 739-744. https://doi.org/10.1634/theoncologist.2015-0429

[9] Darre, T., et al. (2017) Descriptive Epidemiology of Cancers in Togo from 2009 to 2016. Asian Pacific Journal of Cancer Prevention, 18, 3407-3411.

[10] Darre, T., et al. (2017) Breast Cancer Cases of Female Patients under 35 Years of Age in Togo: A Series of 158 Cases. Molecular and Clinical Oncology, 7, 1125-1129.

[11] Tsu, V., Jeronimo, J. and Anderson, B. (2013) Why the Time Is Right to Tackle Breast and Cervical Cancer in Low-Resource Settings. Bulletin of the World Health Organization, 91, 683-690. https://doi.org/10.2471/BLT.12.116020

[12] Samah, A.A., Ahmadian, M. and Latiff, L.A. (2016) Insufficient Knowledge of Breast Cancer Risk Factors among Malaysian Female University Students. Global Journal of Health Science, 8, 277-285. https://doi.org/10.5539/gjhs.v8n1p277

[13] Brinton, L.A., et al. (2017) Design Considerations for Identifying Breast Cancer Risk Factors in a Population-Based Study in Africa. International Journal of Cancer, 140, 2667-2677. https://doi.org/10.1002/ijc.30688

[14] Trimble, E.L. (2017) Breast Cancer in Sub-Saharan Africa. Journal of Global Oncology, 3, 187-188. https://doi.org/10.1200/JGO.2016.008433

[15] Balekouzou, A., et al. (2017) Reproductive Risk Factors Associated with Breast Cancer in Women in Bangui: A Case-Control Study. BMC Women's Health, 17, Article No. 14. https://doi.org/10.1186/s12905-017-0368-0

[16] Rahman, S.A., Al-Marzouki, A., Otim, M., El Hoda Khalil Khayat, N., Yousuf, R. and Rahman, P. (2019) Awareness about Breast Cancer and Breast Self-Examination among Female Students at the University of Sharjah: A Cross-Sectional Study. Asian Pacific Journal of Cancer Prevention, 20, 1901-1908. https://doi.org/10.31557/APJCP.2019.20.6.1901

[17] Sama, C.-B., et al. (2017) Awareness of Breast Cancer and Breast Self-Examination among Female Undergraduate Students in a Higher Teachers Training College in Cameroon. The Pan African Medical Journal, 28, Article 91.

https://doi.org/10.11604/pamj.2017.28.91.10986

[18] Kotepui, M., Piwkham, D., Chupeerach, C. and Duangmano, S. (2015) Knowledge, Attitudes and Practice of Breast Cancer Screening among Female Personnel of Walailak University. Health Expectation, 18, 3069-3078. https://doi.org/10.1111/hex.12292

[19] Sayed, S., et al. (2016) Breast Camps for Awareness and Early Diagnosis of Breast Cancer in Countries with Limited Resources: A Multidisciplinary Model from Kenya. The Oncologist, 21, 1138-1148.

https://doi.org/10.1634/theoncologist.2016-0004 
[20] Dunn, R.A. and Tan, A.K. (2011). Utilization of Breast Cancer Screening Methods in a Developing Nation: Results from a Nationally Representative Sample of Malaysian Households. The Breast Journal, 17, 399-402. https://doi.org/10.1111/j.1524-4741.2011.01098.x

[21] Smith, R.A., et al. (2017) Cancer Screening in the United States, 2017: A Review of Current American Cancer Society Guidelines and Current Issues in Cancer Screening. CA: A Cancer Journal for Clinicians, 67, 100-121.

https://doi.org/10.3322/caac.21392

[22] Heena, H., Durrani, S., Riaz, M., AlFayyad, I., Tabasim, R., Parvez, G. and Abu-Shaheen, A. (2019) Knowledge, Attitudes, and Practices Related to Breast Cancer Screening among Female Health Care Professionals: A Cross Sectional Study. BMC Women's Health, 19, Article No. 122.

https://doi.org/10.1186/s12905-019-0819-x

[23] Darre, T., et al. (2020) Male Breast Cancer in Togo: Imaging and Clinicopathological Findings. International Journal of Breast Cancer, 2020, Article ID: 3056067. https://doi.org/10.1155/2020/3056067

[24] Sambanje, M.N. and Mafuvadze, B. (2012) Breast Cancer Knowledge and Awareness among University Students in Angola. The Pan African Medical Journal, 11, 70 .

[25] Basu, P., et al. (2018) Breast Cancer Screening Program in Morocco: Status of Implementation, Organization and Performance. International Journal of Cancer, 143, 3273-3280. https://doi.org/10.1002/ijc.31749

[26] Darré, T., Folligan, K., Sabi, A., Sonhaye, L., Boumé, A., Bassowa, A., Adani-Ifé, S. and Napo-Koura, G. (2017) Primary Neuroendocrine Breast Carcinoma in a 13-Year-Old Girl: Ultrasonography and Pathology Findings. Case Reports in Radiology, 2017, Article ID: 7915806. https://doi.org/10.1155/2017/7915806

\section{List of Abbreviations}

CI: Confidence Interval

FSS: Faculty of Health Sciences

OR: Adjusted Odds Ratio

UL: University of Lomé 